\title{
Pharmacologic Considerations for Youth with Posttraumatic Stress Disorder
}

\author{
Brooks Keeshin ${ }^{1}$ and Jeffrey R. Strawn ${ }^{2}$ \\ ${ }^{1}$ Department of Pediatrics, University of Utah, Salt Lake City, UT, USA \\ ${ }^{2}$ Department of Psychiatry, University of Cincinnati, Cincinnati, OH, USA
}

\begin{abstract}
Children exposed to potentially traumatic events are at risk of developing posttraumatic stress disorder (PTSD). However, the subsequent developmental course of posttraumatic stress symptoms appears to vary considerably. In this regard, some PTSD symptoms resolve without significant interventions, while for many children and adolescents, they persist until the patient receives appropriate treatment specifically designed to address PTSD and other trauma related symptoms. Evidence-based psychotherapies represent the standard of care for children with PTSD and, while psychopharmacologic interventions are utilized for many youth with posttraumatic stress symptoms and PTSD, there is little data available to guide the use of these medications in this population. However, given the structural challenges involved in disseminating and delivering evidence-based psychotherapies in all settings, prescribing clinicians should be aware of the medications whose use in children with pediatric PTSD has been studied. Herein, we review the PTSD assessment modalities, as well as the use of pharmacologic interventions in PTSD, including antiadrenergic agents, selective serotonin reuptake inhibitors and other medications.
\end{abstract}

Key Words: Posttraumatic stress disorder; Treatment; Medication.

Received: October 16, 2016 / Revision: November 14, 2016 / Accepted: November 15, 2016

Address for correspondence: Brooks Keeshin, Department of Pediatrics, University of Utah, 81 N Mario Capecchi Dr. SLC, UT 84112, USA

Tel: +1-801-662-3605, Fax: +1-801-662-3610, E-mail: brooks.keeshin@hsc.utah.edu

\section{INTRODUCTION}

The Diagnostic and Statistics Manual of Mental Disorders fifth edition (DSM-5) $)^{1)}$ revised the diagnostic criterion for PTSD to be more developmentally sensitive than previous versions, ${ }^{2)}$ while at the same time, identifying a unique qualifier for diagnosing children under 7 with posttraumatic stress disorder (PTSD). Some of the core components of PTSD are similar with only minor changes. ${ }^{3)}$ Studies in both adults as well as children have identified that the shift in criteria from DSM-IV to DSM-5, andthere is still great overlap and prevalence rates are consistent between versions. ${ }^{4)}$ In the United States, phone survey data suggest that up to $80 \%$ of children and adolescents will experience at least one traumatic event in childhood. ${ }^{5)}$ Risk factors for the development of childhood PTSD have been identified, including: female gender, number of traumas experienced, greater exposure to the index trauma, presence of a pre-existing psychiatric disorder, parental psychopathology, and availability of social support (particularly family support). ${ }^{6}$ Although risk factors can help identify those most at risk, when $15-30 \%$ of those who

This is an Open Access article distributed under the terms of the Creative Commons Attribution Non-Commercial License (http://creativecommons.org/licenses/by-nc/3.0) which permits unrestricted non-commercial use, distribution, and reproduction in any medium, provided the original work is properly cited. experience trauma develop PTSD, ${ }^{7,8}$ it is clear that broad based and effective interventions are necessary to address trauma specific symptoms.

Although evidence-based interventions and treatments are urgently needed, the literature does not provide strong support to many of the pharmacotherapies provided to children with known trauma histories and symptoms of PTSD.' This is in contrast to the large body of literature that supports the effectiveness of evidence-based psychotherapies for children and adolescent with PTSD. ${ }^{10)}$ Several components common to evidence based psychotherapies include: providing psychoeducation regarding the common effects of traumatic experiences; developing effective and healthy relaxation skills and coping responses when confronted by intrusive trauma memories or reminders; and accessing family and social supports to enhance safety and routine. ${ }^{11)}$ Over the following sections, we will review effective methods of assessing and treating pediatric PTSD, with a special focus on the limited potential role of pharmacotherapy.

\section{SCREENING FOR TRAUMATIC EXPERIENCES AND TRAUMA SYMPTOMS}

Standardized approaches to the detection of childhood trau- 
ma is critical to identifying children at risk for PTSD. Unfortunately, many children who present to primary care providers or to specialized psychiatric services do not identify traumatic experiences at the time of their initial evaluations, and often times refer to concerns or potentially, to traumarelated symptoms, in commonly used lay terms such as anxiety, depression, or hyperactivity. Moreover, children with a history of trauma exposure are more at risk to develop symptoms of anxiety or depression. ${ }^{12)}$ However, it is also possible for children to meet DSM-5 diagnostic criteria for a number of disorders simply as a result of syndromic overlap, yet for some of those children, their symptoms might be better explained by a unifying diagnosis of PTSD if their trauma is known and trauma specific symptoms are identified. As will be described in detail later, an accurate diagnosis is critical to the appropriate choice of medication as part of a comprehensive treatment plan. Medications that are considered first line treatment for common disorders such as generalized anxiety disorder, panic disorder, major depressive disorder and attention-deficit hyperactivity disorder (ADHD) are not indicated for the treatment of PTSD in trauma exposed children. The use of such medications where there is true co-morbidity may be helpful. However, when syndromic overlap leads a practitioner to misinterpret the hypervigilance and reckless behavior of PTSD for hyperactivity concerning for ADHD, the child is exposed to medication that is not indicated, and initiation of effective treatment is delayed.

Standardized screening measures for trauma symptoms are an effective way to measure trauma symptoms once it has been determined that the child has experienced or witnessed potentially traumatic events. Several of these measures are available in Korean (ref), and others that have been newly developed in the past several years to reflect changes in the diagnosis of PTSD from DSM-IV to DSM- 5 can be requested to be translated and validated. A currently available measure is the Children's Revised Impact of Event Scale, a 13-item measure that detects trauma specific symptoms (http://www.childrenandwar.org/measures/children's-revised-impact-of-event-scale8 ---cries-8/ies13/). The Child PTSD Symptom Scale ${ }^{13)}$ is a 17 item measure with both self-report and parent report formats that identify PTSD symptoms as well as assess for possible functional impairment. The DSM-IV version has been translated into Korean, and the recently developed version for DSM5 (20 items instead of 17) would likely be able to be translated and validated in the future. For symptom detection that is inclusive, but not limited to PTSD specific symptoms, one might consider the Trauma Symptom Checklist for Children (TSCC). ${ }^{14)}$ The TSCC is a 54 item self report measure with strong psychometric properties and validity measures that identifies clinically significant symptoms of anger, anxiety, de- pression, PTSD and dissociative symptoms. The TSCC was recently validated in Korean ${ }^{15}$ and was effective in identifying trauma specific symptoms.

\section{PSYCHOPHARMACOLOGIC APPROACHES FOR YOUTH WITH PTSD}

\section{Antiadrenergic agents}

\section{Propranolol}

Given that research has consistently demonstrated increased noradrenergic tone in both adults (for review see) ${ }^{16)}$ and youth with PTSD, ${ }^{17)}$ several investigators have explored the efficacy of anti-adrenergic agents for the prevention and treatment of PTSD. Propranolol is a centrally-acting, long-chain $\beta$-blocker that is used primarily for hypertension, and has been used off-label for the treatment of situational anxiety, such a stage fright or performance anxiety. Famularo et al. ${ }^{18)}$ demonstrated reductions in PTSD symptoms, and observed that propranolol was well tolerated. However, there are significant reasons for cautions when viewing Famularo et al's findings. Specifically, there was no documentation to the presence or absence of a co-morbid anxiety disorder, which given the accepted use of propranolol, could impact reported improvement by children, and there was no control group, a common issue in open label trials. Additionally, more rigorous studies examining the use of propranolol among trauma exposed youth have had negative results. Specifically, in a PTSD prevention study, children and adolescents aged $10-18$ years were randomized to receive propranolol or placebo shortly after a potentially traumatic event. At follow up, there were no significant differences in PTSD severity or PTSD diagnosis at 6-week follow-up. ${ }^{19)}$ Given the underlying noradrenergic dysregulation hypothesis that explains many of the symptoms of PTSD, these negative prevention studies likely reflect a lack of overall efficacy in either the prevention or treatment of PTSD in youth.

\section{Prazosin}

Prazosin is a centrally acting alpha 1 blocking agent that blocks the effect of norepinephrnine centrally, and adult studies demonstrate effectiveness in randomized controlled trials and other large comparative studies. ${ }^{20-22)}$ Several case reports suggest benefit for prazosin ${ }^{23-26)}$ in youth diagnosed with PTSD. The use of prazosin is limited to evening dose, focusing on the treatment of PTSD related sleep disturbances and nightmares. Increased sympathetic nervous system activity is associated with pediatric PTSD, especially intrusive and hyperarousal sympotms. ${ }^{17,27,28)}$ However, caution is warranted as there are no large, double-blind, placebo-controlled 
trials that demonstrate safety or efficacy of prazosin in children.

\section{$\alpha_{2}$ agonists}

$\mathrm{a}_{2}$ agonists such as clonidine and guanfacine are regularly used as second line agents in the treatment of $\mathrm{ADHD},{ }^{29)}$ as well as aggression in children. Based on the theoretical construct that many of the symptoms of PTSD are likely related to sympathetic nervous system dysregulation, ${ }^{17)}$ and the known tolerability, it is reasonable to consider the use of these agents in trauma exposed children with severe trauma related behavioral manifestations who are not responding to first line psychotherapies. However, similar to prazosin, caution is advised as there is little evidence to support the use of these agents. Clonidine appears to attenuate hyperarousal, hypervigilance, sleep disruption, exaggerated startle responses and nightmares in open label trials. In abused youth, clonidine decreases reenactment symptoms. ${ }^{30,31)}$ Similarly, the $\alpha_{2}$ agonist guanfacine may reduce nightmares in children with PTSD. ${ }^{32)}$ However, when extended-release guanfacine was examined with regard to the treatment of PTSD symptoms, although improvements were noted for the UCLA Reaction Index scores for reexperiencing, avoidant, and hyperarousal symptoms, ${ }^{33)}$ most children with nightmares did not experience resolution of their nightmares while taking extended-release guanfacine. Of note, guanfacine was well tolerated and adverse events were consistent with the known side effect profile of this medication. ${ }^{34)}$

\section{Antidepressant medications}

Several selective serotonin reuptake inhibitors (SSRIs), including sertraline and paroxetine, are FDA approved for the treatment of adults with PTSD. Unfortunately, this is a clear area of pharmacotherapy that highlights the benefit of researching the effects of treatment on pediatric conditions rather than extrapolating adult findings to the care of children and adolescents. ${ }^{35)}$ Two open-label studies suggest improvement in PTSD symptoms in youth treated with citalopram, ${ }^{36,37)}$ however, two randomized controlled trials failed to demonstrate benefit with sertraline in youth with PTSD compared to placebo. Adjunctive sertraline (mean dose $150 \mathrm{mg} /$ day, range 50-200 mg/day) vs. placebo combined with traumafocused cognitive behavioral therapy (TF-CBT) yielded only limited improvement in the sertraline-treated youth, ${ }^{38)}$ although this study was underpowered to detect differences in efficacy. A subsequent 10 week trial of sertraline monotherapy did not result in significant differences (compared to placebo) in PTSD or depression symptoms. ${ }^{39)}$

\section{Other medications}

Second generation antipsychotics (SGA) such as quetiap- ine and risperidone have been examined in youth with PTSD and these open label studies and case series have demonstrated improvement in trauma specific symptoms. ${ }^{40-42)}$ However, even these small, uncontrolled studies have consistently found the development of significant side effects including weight gain among treated youth. Given the risk of obesity among trauma exposed youth in both childhood and adulthood, the availability of other medications without the significant risk of weight gain, and the lack of evidence supporting the use of SGAs, there is little role in the use of SGAs among most children with PTSD. The same can be said for mood stabilizers such as carbamazepine, divalproex and oxcarbazepine, all of which have open label trial or retrospective case series evidence demonstrating that use of medication was associated with some improvement in PTSD symptoms. ${ }^{43-45)}$

\section{PSYCHOTHERAPEUTIC INTERVENTIONS}

Evidence based and trauma focused psychotherapies are the gold standard in the treatment of pediatric PTSD. Numerous professional organizations, guidelines and meta-analyses support the use of psychotherapies in the treatment of traumatized children. ${ }^{46)}$ Although not universally available, it is critical that the practicing child psychiatrist understand and advocate for the dissemination and implementation of these modalities in both specialized and community settings. Numerous therapies have been developed and tested in a number of different countries with different trauma exposed populations. A comprehensive review of all evidence-based modalities is beyond the scope of this review. However, two examples of effective interventions, Trauma Focused Cognitive Behavior Therapy ${ }^{47)}$ and Child and Family Traumatic Stress Intervention ${ }^{48)}$ will highlight components and strengths common to many interventions. Additional information, including information on interventions can be found on the National Child Traumatic Stress Network website (http://nctsn. $\operatorname{org} /)$.

\section{Trauma focused cognitive behavioral therapy}

TF-CBT is a manualized and stepwise approach to the treatment of children and adolescents 3-17 years of age who have trauma related symptoms. ${ }^{47)}$ Children and adolescents who benefit from TF-CBT include those with PTSD, anxiety, depressive or externalizing behaviors. Randomized controlled trials comparing TF-CBT efficacy against other psychotherapies have been performed by multiple investigators who have replicated findings of the original treatment developers. ${ }^{9,10)}$ Furthermore, TF-CBT offers the opportunity to address commonly experienced psychological sequallae of traumatic experiences such as childhood sexual abuse such as 
traumatic sexualization, betrayal, feeling powerless and stigmatization. ${ }^{49)}$ TF-CBT is generally provided over $12-24$ weeks for symptoms that result from a single episode of trauma, but might last longer for children and adolescents who suffer from polyvictimization. ${ }^{50)}$

TF-CBT consists of psychoeducational, stress reduction and cognitive coping components as well as the development of a trauma narrative. The goal of the trauma narrative is to provide the child or adolescent with gradual exposure to the troubling memories in a safe environment where the therapist can help the child utilize skills learned during therapy to decrease distress and correct ongoing cognitive distortions that often perpetuate symptoms. Once the child has completed the trauma narrative, the focus of therapy moves towards re-establishing the normal parent-child dynamic, supporting the child in sharing the narrative with the parent and encouraging the establishment of improved communication within the family as well as safety guidance to prevent subsequent traumas.

Although the trauma narrative is considered a core component of TF-CBT, some evidence suggests that not all children need the narrative to have significant reduction in symptoms, especially when provided the psychoeducation, relaxation skills and cognitive coping strategies. One randomized controlled trial demonstrated that children who received TFCBT with versus without a trauma narrative demonstrated similar symptom improvement, especially when the trauma narrative was replaced with additional coping skills and parental guidance. ${ }^{51)}$ Child Family Traumatic Stress Intervention (CFTSI) is a similarly effective, family based, PTSD prevention program that also focuses on skills without a discrete exposure component such as a trauma narrative. ${ }^{48)}$ CFTSI is best suited for recently traumatized children with new onset of symptoms or worsening symptoms shortly after the trauma and can be provided over four to six sessions. CFTSI focuses on the identification of trauma symptoms as observed by the parent and experienced by the child. After identifying current trauma symptoms, the remainder of the psychotherapy focuses on enhancing communication within the family about the child's symptoms and utilizing specific coping strategies to decrease symptom specific distress. In a randomized controlled trial of recently traumatized youth comparing CFTSI to supportive therapy ( $\mathrm{n}=106$, ages $7-17$ years), CFTSI-treated patients were $65 \%$ less likely to meet DSM-IV criteria for PTSD at 3-month follow-up than youth in the comparison group. CFTSI was also associated with lower levels of behavior avoidance and re-experiencing of the event. When necessary, CFTSI can transition to more definitive treatments for PTSD such as TF-CBT in children who need more comprehensive trauma treatment after the initial $4-6$ sessions.

\section{CONCLUSION}

Children and adolescents exposed to potentially traumatic events are at risk for the development of PTSD. Evidence based interventions exists and are effective in the treatment of pediatric PTSD, yet the overwhelming evidence supports the use of psychotherapeutic modalities over psychopharmacologic interventions. In cases where medication may be warranted to augment the effect of psychotherapy, the biological underpinnings of PTSD (dysregulation of the stress response systems) as well as side effect profiles suggest the cautious and limited use of antiadrenergic agents be considered. There is no evidence that strongly supports the use of SSRIs without clear anxiety or depression co-morbidity. Finally, SGAs and mood stabilizers are not recommended for the treatment of pediatric PTSD given the lack of supporting evidence and side effect profile.

\section{Acknowledgments}

Dr. Keeshin receives support from Substance Abuse and Mental Health Administration. Dr. Strawn has received research support from Eli Lilly, Shire, Forest, Lundbeck, Neuronetics and from the American Academy of Child \& Adolescent Psychiatry and the National Institutes of Health.

\section{Conflicts of Interest}

The authors have no financial conflicts of interest.

\section{REFERENCES}

1) American Psychiatric Association. Diagnostic and Statistical Manual of Mental Disorders (DSM-5). 5th ed. Arlington: American Psychiatric Publishing;2013.

2) Nemeroff CB, Weinberger D, Rutter M, MacMillan HL, Bryant RA, Wessely S, et al. DSM-5: a collection of psychiatrist views on the changes, controversies, and future directions. BMC Med 2013; 11:202.

3) Scheeringa MS. Developmental considerations for diagnosing PTSD and acute stress disorder in preschool and school-age children. Am J Psychiatry 2008;165:1237-1239.

4) Hafstad GS, Dyb G, Jensen TK, Steinberg AM, Pynoos RS. PTSD prevalence and symptom structure of DSM- 5 criteria in adolescents and young adults surviving the 2011 shooting in Norway. J Affect Disord 2014;169:40-46.

5) Finkelhor D, Turner HA, Shattuck A, Hamby SL. Prevalence of childhood exposure to violence, crime, and abuse: results from the national survey of children's exposure to violence. JAMA Pediatr 2015;169:746-754.

6) Scheeringa MS, Wright MJ, Hunt JP, Zeanah CH. Factors affecting the diagnosis and prediction of PTSD symptomatology in children and adolescents. Am J Psychiatry 2006;163:644-651.

7) Daviss WB, Mooney D, Racusin R, Ford JD, Fleischer A, McHugo GJ. Predicting posttraumatic stress after hospitalization for pediatric injury. J Am Acad Child Adolesc Psychiatry 2000;39:576-583.

8) Stallard P, Velleman R, Baldwin S. Prospective study of post-traumatic stress disorder in children involved in road traffic accidents. BMJ 1998;317:1619-1623.

9) Keeshin BR, Strawn JR. Psychological and pharmacologic treatment of youth with posttraumatic stress disorder: an evidence-based 
review. Child Adolesc Psychiatr Clin N Am 2014;23:399-411, x.

10) Morina N, Koerssen R, Pollet TV. Interventions for children and adolescents with posttraumatic stress disorder: a meta-analysis of comparative outcome studies. Clin Psychol Rev 2016;47:41-54.

11) Cohen JA, Kelleher KJ, Mannarino AP. Identifying, treating, and referring traumatized children: the role of pediatric providers. Arch Pediatr Adolesc Med 2008;162:447-452.

12) Pine DS, Cohen JA. Trauma in children and adolescents: risk and treatment of psychiatric sequelae. Biol Psychiatry 2002;51:519-531.

13) Foa EB, McLean CP, Capaldi S, Rosenfield D. Prolonged exposure vs supportive counseling for sexual abuse-related PTSD in adolescent girls: a randomized clinical trial. JAMA 2013;310:2650-2657.

14) Sadowski CM, Friedrich WN. Psychometric properties of the trauma symptom checklist for children (TSCC) with psychiatrically hospitalized adolescents. Child Maltreat 2000;5:364-372.

15) Chung US. The Korean version of the trauma symptom checklist for children: psychometric properties and the connection to trauma among Korean children and adolescents. J Korean Med Sci 2014;29: 837-845.

16) Strawn JR, Geracioti TD Jr. Noradrenergic dysfunction and the psychopharmacology of posttraumatic stress disorder. Depress Anxiety $2008 ; 25: 260-271$

17) Keeshin BR, Strawn JR, Out D, Granger DA, Putnam FW. Elevated salivary alpha amylase in adolescent sexual abuse survivors with posttraumatic stress disorder symptoms. J Child Adolesc Psychopharmacol 2015;25:344-350.

18) Famularo R, Kinscherff R, Fenton T. Propranolol treatment for childhood posttraumatic stress disorder, acute type. A pilot study. Am J Dis Child 1988;142:1244-1247.

19) Nugent NR, Christopher NC, Crow JP, Browne L, Ostrowski S, Delahanty DL. The efficacy of early propranolol administration at reducing PTSD symptoms in pediatric injury patients: a pilot study. J Trauma Stress 2010;23:282-287.

20) Raskind MA, Peskind ER, Hoff DJ, Hart KL, Holmes HA, Warren D, et al. A parallel group placebo controlled study of prazosin for trauma nightmares and sleep disturbance in combat veterans with post-traumatic stress disorder. Biol Psychiatry 2007;61:928-934.

21) Raskind MA, Thompson C, Petrie EC, Dobie DJ, Rein RJ, Hoff DJ, et al. Prazosin reduces nightmares in combat veterans with posttraumatic stress disorder. J Clin Psychiatry 2002;63:565-568.

22) Byers MG, Allison KM, Wendel CS, Lee JK. Prazosin versus quetiapine for nighttime posttraumatic stress disorder symptoms in veterans: an assessment of long-term comparative effectiveness and safety. J Clin Psychopharmacol 2010;30:225-229.

23) Brkanac Z, Pastor JF, Storck M. Prazosin in PTSD. J Am Acad Child Adolesc Psychiatry 2003;42:384-385.

24) Oluwabusi OO, Sedky K, Bennett DS. Prazosin treatment of nightmares and sleep disturbances associated with posttraumatic stress disorder: two adolescent cases. J Child Adolesc Psychopharmacol 2012;22:399-402.

25) Strawn JR, Delbello MP, Geracioti TD. Prazosin treatment of an adolescent with posttraumatic stress disorder. J Child Adolesc Psychopharmacol 2009;19:599-600.

26) Strawn JR, Keeshin BR. Successful treatment of posttraumatic stress disorder with prazosin in a young child. Ann Pharmacother 2011; 45:1590-1591.

27) De Bellis MD, Baum AS, Birmaher B, Ryan ND. Urinary catecholamine excretion in childhood overanxious and posttraumatic stress disorders. Ann N Y Acad Sci 1997;821:451-455.

28) Pervanidou P. Biology of post-traumatic stress disorder in childhood and adolescence. J Neuroendocrinol 2008;20:632-638.

29) Bloch MH, Panza KE, Landeros-Weisenberger A, Leckman JF. Meta-analysis: treatment of attention-deficit/hyperactivity disorder in children with comorbid tic disorders. J Am Acad Child Adolesc Psychiatry 2009;48:884-893.
30) Harmon RJ, Riggs PD. Clonidine for posttraumatic stress disorder in preschool children. J Am Acad Child Adolesc Psychiatry 1996;35: 1247-1249.

31) Porter DM, Bell CC. The use of clonidine in post-traumatic stress disorder. J Natl Med Assoc 1999;91:475-477.

32) Horrigan JP, Barnhill LJ. The suppression of nightmares with guanfacine. J Clin Psychiatry 1996;57:371.

33) Connor DF, Grasso DJ, Slivinsky MD, Pearson GS, Banga A. An open-label study of guanfacine extended release for traumatic stress related symptoms in children and adolescents. J Child Adolesc Psychopharmacol 2013;23:244-251.

34) Sallee FR, Lyne A, Wigal T, McGough JJ. Long-term safety and efficacy of guanfacine extended release in children and adolescents with attention-deficit/hyperactivity disorder. J Child Adolesc Psychopharmacol 2009;19:215-226.

35) Strawn JR, Keeshin BR, DelBello MP, Geracioti TD Jr, Putnam FW. Psychopharmacologic treatment of posttraumatic stress disorder in children and adolescents: a review. J Clin Psychiatry 2010; 71:932-941

36) Seedat S, Lockhat R, Kaminer D, Zungu-Dirwayi N, Stein DJ. An open trial of citalopram in adolescents with post-traumatic stress disorder. Int Clin Psychopharmacol 2001;16:21-25.

37) Seedat S, Stein DJ, Ziervogel C, Middleton T, Kaminer D, Emsley RA, et al. Comparison of response to a selective serotonin reuptake inhibitor in children, adolescents, and adults with posttraumatic stress disorder. J Child Adolesc Psychopharmacol 2002;12:37-46.

38) Cohen JA, Mannarino AP, Perel JM, Staron V. A pilot randomized controlled trial of combined trauma-focused CBT and sertraline for childhood PTSD symptoms. J Am Acad Child Adolesc Psychiatry 2007;46:811-819.

39) Robb AS, Cueva JE, Sporn J, Yang R, Vanderburg DG. Sertraline treatment of children and adolescents with posttraumatic stress disorder: a double-blind, placebo-controlled trial. J Child Adolesc Psychopharmacol 2010;20:463-471.

40) Stathis S, Martin G, McKenna JG. A preliminary case series on the use of quetiapine for posttraumatic stress disorder in juveniles within a youth detention center. J Clin Psychopharmacol 2005;25:539544.

41) Meighen KG, Hines LA, Lagges AM. Risperidone treatment of preschool children with thermal burns and acute stress disorder. J Child Adolesc Psychopharmacol 2007;17:223-232.

42) Keeshin BR, Strawn JR. Risperidone treatment of an adolescent with severe posttraumatic stress disorder. Ann Pharmacother 2009; 43:1374.

43) Looff D, Grimley P, Kuller F, Martin A, Shonfield L. Carbamazepine for PTSD. J Am Acad Child Adolesc Psychiatry 1995;34:703704.

44) Steiner H, Saxena KS, Carrion V, Khanzode LA, Silverman M, Chang K. Divalproex sodium for the treatment of PTSD and conduct disordered youth: a pilot randomized controlled clinical trial. Child Psychiatry Hum Dev 2007;38:183-193.

45) Staller JA, Kunwar A, Simionescu M. Oxcarbazepine in the treatment of child psychiatric disorders: a retrospective chart review. J Child Adolesc Psychopharmacol 2005;15:964-969.

46) Cohen JA, Bukstein O, Walter H, Benson SR, Chrisman A, Farchione TR, et al. Practice parameter for the assessment and treatment of children and adolescents with posttraumatic stress disorder. J Am Acad Child Adolesc Psychiatry 2010;49:414-430.

47) Cohen JA, Mannarino AP, Iyengar S. Community treatment of posttraumatic stress disorder for children exposed to intimate partner violence: a randomized controlled trial. Arch Pediatr Adolesc Med 2011;165:16-21.

48) Berkowitz SJ, Stover CS, Marans SR. The Child and Family Traumatic Stress Intervention: secondary prevention for youth at risk of developing PTSD. J Child Psychol Psychiatry 2011;52:676-685. 
49) Finkelhor D, Browne A. The traumatic impact of child sexual abuse: a conceptualization. Am J Orthopsychiatry 1985;55:530-541.

50) Connor DF, Ford JD, Arnsten AF, Greene CA. An update on posttraumatic stress disorder in children and adolescents. Clin Pediatr (Phila) 2015;54:517-528.
51) Deblinger E, Mannarino AP, Cohen JA, Runyon MK, Steer RA. Trauma-focused cognitive behavioral therapy for children: impact of the trauma narrative and treatment length. Depress Anxiety 2011; 28:67-75. 